\title{
Vagal stimulation exaggerates the inhibitory ghrelin response to oral fat in humans
}

\author{
R B Heath, R Jones, K N Frayn and M D Robertson \\ Oxford Centre for Diabetes, Endocrinology and Metabolism, University of Oxford, Oxford, UK \\ (Requests for offprints should be addressed to M D Robertson, Oxford Lipid Metabolism Group, OCDEM, Churchill Hospital, Oxford, OX3 7 L), UK; \\ Email: denise.robertson@oxlip.ox.ac.uk)
}

\begin{abstract}
Ghrelin, the growth hormone secretagogue receptor ligand, is a key regulator of adiposity and food intake. However, the regulation of ghrelin in response to dietary fat intake remains largely unclear. Furthermore, cephalic elevation of ghrelin may influence fat absorption and postprandial lipaemia. Therefore, the aim of this study was to examine the effect of fat ingestion and vagal stimulation on the regulation of plasma ghrelin.

Vagal stimulation was achieved by modified sham feeding (MSF). Eight healthy subjects (four male/four female) consumed a $50 \mathrm{~g}$ fat load on two separate occasions. On one occasion, the fat load was preceded by the
\end{abstract}

MSF of a meal for $1 \mathrm{~h}$. Blood, appetite and breath were analysed for $5 \mathrm{~h}$ postprandially.

A $25 \%$ (S.E.M. 3.4) suppression in ghrelin concentration was observed after fat ingestion $(P<0.001)$, without an increase in glucose or insulin. MSF in addition to oral fat enhanced ghrelin suppression further, as well as elevating plasma triacylglycerol $(P<0 \cdot 001)$ and reducing appetite $(P<0 \cdot 001)$. The fasting ghrelin concentration was inversely correlated with gastric half-emptying time $(P=0 \cdot 036)$.

We conclude that ghrelin release may be influenced directly by both vagal stimulation and oral fat ingestion.

Journal of Endocrinology (2004) 180, 273-281

\section{Introduction}

Ghrelin has recently been identified as the endogenous ligand for the growth hormone secretagogue receptor (Kojima et al. 1999, Tschöp et al. 2000). Hunger is often noted as a side-effect when i.v. ghrelin is given to increase growth hormone secretion in human subjects (Arvat et al. 2001, Wren et al. 2001). Administration of ghrelin to rodents has been shown to increase food intake and reduce fat oxidation (Nakazato et al. 2001), leading to adiposity (Tschöp et al. 2000). Despite the link between adiposity, food intake and plasma ghrelin concentrations, the mechanisms behind ghrelin regulation remain unclear.

Plasma ghrelin is highly suppressed in the postprandial period (Cummings et al. 2001, Tschöp et al. 2001a). To date, postprandial ghrelin concentrations have only been studied following meals containing a significant amount of carbohydrate. Elevated glucose and insulin concentrations have been suggested as potential regulators of postprandial ghrelin (Toshinai et al. 2001, Lucidi et al. 2002, McCowen et al. 2002, Saad et al. 2002, Shiiya et al. 2002). A more recent study (Schaller et al. 2003) has demonstrated that physiological elevations in plasma glucose or insulin concentrations have little effect on the amount of circulating ghrelin. The correlation between body mass index and plasma ghrelin (Tschöp et al. 2001b) suggests that plasma ghrelin concentrations may be associated with lipid metab- olism. Elevation of plasma non-esterified fatty acid (NEFA) concentrations using Intralipid-heparin infusions has no effect on circulating ghrelin concentrations (Mohlig et al. 2002); however, this does not necessarily reflect the situation seen following fat ingestion. For example, gastric emptying of nutrients plays a critical role in postprandial ghrelin suppression (Tschöp et al. 2000, Williams et al. 2003). The extent to which gastric emptying of dietary fat may affect postprandial ghrelin suppression remains to be assessed.

Ingestion of pure fat has been shown to have very little effect on plasma insulin and glucose concentrations (Evans et al. 2001), therefore providing a method for assessing postprandial ghrelin regulation, independently of changes in either insulin or glucose concentrations. Oral fat has been previously used to assess the effect of cephalic-phase hormone responses on postprandial metabolism. Cephalicphase responses are physiological changes initiated by stimulation of the vagus nerve in response to food cues such as the thought, sight, smell and taste of palatable food (Naim et al. 1978). The primary metabolic changes occurring in this preprandial period are gallbladder contraction (Hopman et al. 1987), gastrin and gastric acid production (Feldman \& Richardson 1986), and stimulation of both the exocrine and endocrine pancreas (Konturek \& Konturek 2000). The cephalic phase of insulin secretion is now regarded as important in 
determining postprandial glucose tolerance (Calles Escandon \& Robbins 1987, Teff \& Engelman 1996).

Cephalic-phase elevation in ghrelin has been suggested to trigger food intake, and may in part influence the subsequent processing of food. The vagus nerve has been shown to be intrinsically linked to both ghrelin regulation (Lee et al. 2002) and action (Masuda et al. 2000). Vagotomy elevates plasma ghrelin significantly (Lee et al. 2002), whereas electrical stimulation of the vagus nerve tends to decrease ghrelin in rats (Murakami et al. 2002). Habitual purging in patients with bulimia nervosa (Tanaka et al. 2002) has provided indirect evidence of a potential link between vagal activity and fasting ghrelin concentrations. However, the effects of vagal stimulation on ghrelin regulation have not been properly assessed in humans.

The aim of the current study was to investigate gastrointestinal modulation of plasma ghrelin by examining the effect of fat ingestion and vagal stimulation on postprandial ghrelin secretion in healthy humans. Vagal stimulation was achieved using the modified sham feeding (MSF) technique, as described previously (Jackson et al. 2001, Robertson et al. 2001, 2002). The maximal effects are achieved when MSF precedes an oral load, effects of which have been shown to extend well into the postprandial period (Robertson et al. 2001, 2002).

\section{Materials and Methods}

\section{Subjects}

Eight healthy subjects (four male, four female) were studied on two separate occasions. The mean age was 22.5 years (range $21-25$ ) and the mean body mass index was $22 \cdot 5 \mathrm{~kg} / \mathrm{m}^{2}$ (range 18.2-26.7). Subjects had a fasting mean plasma glucose concentration of $4.9 \mathrm{mmol} / 1$ (range $4 \cdot 0$ $5 \cdot 2$ ) and a mean fasting plasma triacylglycerol (TG) concentration of $1 \cdot 0 \mathrm{mmol} / 1$ (range $0 \cdot 5-1 \cdot 7$ ). The study was approved by the Oxfordshire Clinical Research Ethics Committee and all subjects gave informed consent before the study.

\section{Study protocol}

To standardize the subjects' nutritional state before the study, all the subjects consumed a low-fat ( $<10 \mathrm{~g}$ fat) evening meal to reduce 'spill-over' effects on plasma TG levels (Fielding et al. 1996). All subjects were instructed to fast overnight, and to refrain from alcohol and strenuous exercise. A cannula was inserted into an antecubital vein, and a fasting sample was taken at $\mathrm{t}=-60 \mathrm{~min}$. A standard, pure high-fat liquid test meal (oral fat load) containing $466 \mathrm{~kJ}$ and $50 \mathrm{~g}$ long-chain TGs (SHS International Ltd, Liverpool, UK) was consumed at $\mathrm{t}=0 \mathrm{~min}$. Each subject participated in both test protocols, which were random- ized. The protocols were as follows: (A) the oral fat load, or (B) the oral fat load preceded by MSF. Blood sampling was performed every $15 \mathrm{~min}$ for $60 \mathrm{~min}$ preceding the oral fat load, and at 15-30 min intervals for $300 \mathrm{~min}$ postprandially.

\section{MSF}

All food used for sham feeding was prepared in a room separated from the clinical area. The MSF involved the subjects masticating and expectorating one-quarter of the total test meal every $15 \mathrm{~min}$ for a total of $1 \mathrm{~h}$. The MSF was performed at $\mathrm{t}=-60,-45,-30$ and $-15 \mathrm{~min}$. Subjects were provided with known volumes of water to rinse out their mouths to aid the removal of the food. The meal chosen consisted of a cheese and tomato pizza and a milk and cream drink ( $38 \mathrm{~g}$ fat, $53 \mathrm{~g}$ carbohydrate and $2733 \mathrm{~kJ}$ ). This test meal has been used successfully in other sham-feeding studies (Jackson et al. 2001, Robertson et al. 2001, 2002). The MSF meal was weighed before and after the study. The expectorated meal was then homogenized in a Waring blender (Dynamics Corporation of America, New Hartford, CT, USA) and a sample was analysed for TG content. Lipids from the meal were extracted in a solution of 2:1 chloroform:methanol followed by transesterification with acidified methanol. Total fatty acid analysis was performed with a Chrompack 9000 gas chromatograph (Varian UK, Walton-on-Thames, UK) with heptadecanoic acid as the internal standard (Fielding et al. 1996).

\section{Blood collection and analysis}

Blood samples were collected into heparinized syringes (Sarstedt, Leicester, Leics, UK), for analysis of plasma metabolites and insulin. Plasma was separated by centrifugation at $1700 \boldsymbol{g}$ for $15 \mathrm{~min}$. Samples for plasma TG, NEFA and insulin analysis were stored at $-20{ }^{\circ} \mathrm{C}$ until analysed. Whole blood for pancreatic polypeptide (PP) was divided into plain tubes and after clotting, serum was stored at $-80{ }^{\circ} \mathrm{C}$ until analysis. Blood samples for ghrelin were collected into potassium EDTA-coated tubes containing $200 \mathrm{kIU}$ aprotinin/ml blood (Trasylol; Bayer plc, Newbury, Berks, UK), centrifuged at $1700 \boldsymbol{g}$ for $15 \mathrm{~min}$ and plasma stored at $-20{ }^{\circ} \mathrm{C}$ until analysis.

Plasma glucose and TG concentrations were measured with kits from Instrumentation Laboratory (Warrington, Cheshire, UK) and NEFA concentrations were measured with kits from Alpha Laboratories (Eastleigh, Hants, UK). These metabolites were measured enzymatically with an IL Monarch automated analyser (Instrumentation Laboratory). The metabolites were all batch-analysed and exhibited an intra-assay coefficient of variation (CV) of $<2 \cdot 5 \%$. Insulin was measured with a commercially available kit (Pharmacia \& Upjohn, Milton Keynes, Bucks, UK). 
Serum PP was analysed using a commercially available RIA (Eurodiagnostica, Boldon, Tyne and Wear, UK). Total ghrelin was analysed using a commercially available RIA (Linco, St Louis, MO, USA). RIA antibodies were raised against the $\mathrm{C}$-terminal region (acylated and desacylated ghrelin) and showed no detected cross-reactivity with motilin-related peptide. The sensitivity of this assay was $10 \mathrm{pg} / \mathrm{ml}$. All samples for hormone analysis were frozen according to the kit manufacturers' instructions. Hormones were batch analysed and exhibited an intra-assay $\mathrm{CV}$ of $<10 \%$.

\section{Measurements of gastric emptying}

Gastric emptying parameters were calculated using the $\left[1-{ }^{13} \mathrm{C}\right]$ octanoic acid breath test, which has been validated and described in detail previously (Maes et al. 1998, Symonds et al. 2000). Briefly, $\left[1-{ }^{13} \mathrm{C}\right]$ octanoic acid was added to the oral fat load, for ingestion at $\mathrm{t}=0 \mathrm{~min}$. Breath samples were taken every $15 \mathrm{~min}$ between $\mathrm{t}=0 \mathrm{~min}$ and $\mathrm{t}=120 \mathrm{~min}$, then at $30 \mathrm{~min}$ intervals between $\mathrm{t}=120 \mathrm{~min}$ and $\mathrm{t}=180 \mathrm{~min}$. Expelled $\mathrm{CO}_{2}$ was collected in two evacuated glass tubes (Isochem Ltd, Wokingham, Berks, UK) at each time point and analysed using isotope-ratio mass spectrometry. The endogenous $\mathrm{CO}_{2}$ production during the study was assumed to be constant (Ghoos et al. 1993 ) at $5 \mathrm{mmol} / 1 \mathrm{CO}_{2} / \mathrm{m}^{2}$ body surface area per min (Haycock et al. 1978). The change in the ${ }^{13} \mathrm{C} /{ }^{12} \mathrm{C}$ ratio in $\mathrm{CO}_{2}$ was determined as the difference above baseline compared with the international standard for ${ }^{13} \mathrm{C}$ abundance (Pee Dee Belemnite). The results are expressed as both percentage ${ }^{13} \mathrm{C}$ recovery/min and cumulatively over $180 \mathrm{~min}$

\section{Visual analogue score (VAS)}

Subjects were asked to fill in 'appetite' questionnaires at hourly intervals during the study protocol, as described previously (Flint et al. 2000). The questionnaires use a $10 \mathrm{~cm}$ graduated line-scale to assess the subject's mood throughout the study period. The questionnaire is designed to measure an individual's eating behaviour and was used to determine if an individual's attitude toward food could be correlated with a particular physiological response.

\section{Statistics}

Data were analysed with the Statistical Package for the Social Sciences (SPSS) software version 10.0 (SPSS UK Ltd, Chertsey, Surrey, UK). Normal distribution was assessed using the Shapiro-Wilkes test. Preprandial and postprandial differences in the metabolite and hormone responses between the two protocols were analysed by repeated-measures ANOVA, using 'time' and 'protocol' as the within-subject factors when normally distributed. Area under the curve (AUC) and integrated area under the curve (iAUC) were calculated by using the trapezoidal method. Summary statistics (peak, height, time to peak and AUC) were compared by using a one-way ANOVA combined with a post-hoc Tukey test. Partial correlations (controlling for subject) were also performed between metabolites using Pearson's correlation with a two-tailed significance test. $P<0.05$ was considered statistically significant. Data are expressed as mean \pm S.E.M.

\section{Results}

\section{Plasma hormones}

Plasma ghrelin concentrations changed in response to both the MSF with oral fat and oral fat alone protocols. Prior to the test meal, there was a rise in plasma ghrelin concentrations. A significantly higher preprandial increase $(P=0 \cdot 024,143$ vs $244 \mathrm{ng} / \mathrm{ml}$ change from $\mathrm{t}=-60$ to $\mathrm{t}=0$, Fig. 1a) was observed with additional MSF (vagal stimulation). There was significant suppression of plasma ghrelin concentration (time, $P<0 \cdot 001$ ) following food intake. In the postprandial period, plasma ghrelin concentrations fell by $517 \cdot 8 \pm 95 \cdot 0 \mathrm{pg} / \mathrm{ml}$ after the fat load alone, whereas there was significantly more suppression $(715 \cdot 0 \pm 139 \cdot 1 \mathrm{pg} / \mathrm{ml}$ ) with additional MSF (protocol $\times$ time interaction, $P<0.009$ ). Following oral fat alone, the decline in ghrelin concentration was not immediate, i.e. levels continuing to rise for a further $15 \mathrm{~min}$ postingestion. This is in contrast to oral fat with MSF, which showed no delay in ghrelin suppression.

Significant PP responses were observed both preprandially (protocol, $P=0.002$ ) and postprandially (protocol $\times$ time, $P=0.048$, Fig. 1b). A biphasic pattern in PP concentrations was observed during the MSF protocol, with peaks at $\mathrm{t}=-30 \mathrm{~min}$ (preprandial) and $\mathrm{t}=15 \mathrm{~min}$ (postprandial). The preprandial peak was not observed in the normal fat feeding protocol, but a small postprandial peak was still observed at $\mathrm{t}=15 \mathrm{~min}$.

Plasma insulin levels remained within the fasting range during both the preprandial and postprandial periods, with no significant difference between the two protocols (Fig. 1c).

\section{Gastric emptying}

The effects of MSF and oral fat ingestion on mean rate of recovery of ${ }^{13} \mathrm{CO}_{2}$ in breath after ingestion of labelled octanoic acid are shown in Fig. 2a. The initial rate of recovery was identical for both protocols. By $t=75 \mathrm{~min}$, the rate of label recovery was significantly higher after MSF than that of oral fat ingestion alone (protocol $\times$ time interaction, $P=0 \cdot 001)$. When expressed as cumulative recovery (Fig. 2b), the total amount of label recovered after $4 \mathrm{~h}$ was higher after MSF compared with fat ingestion 

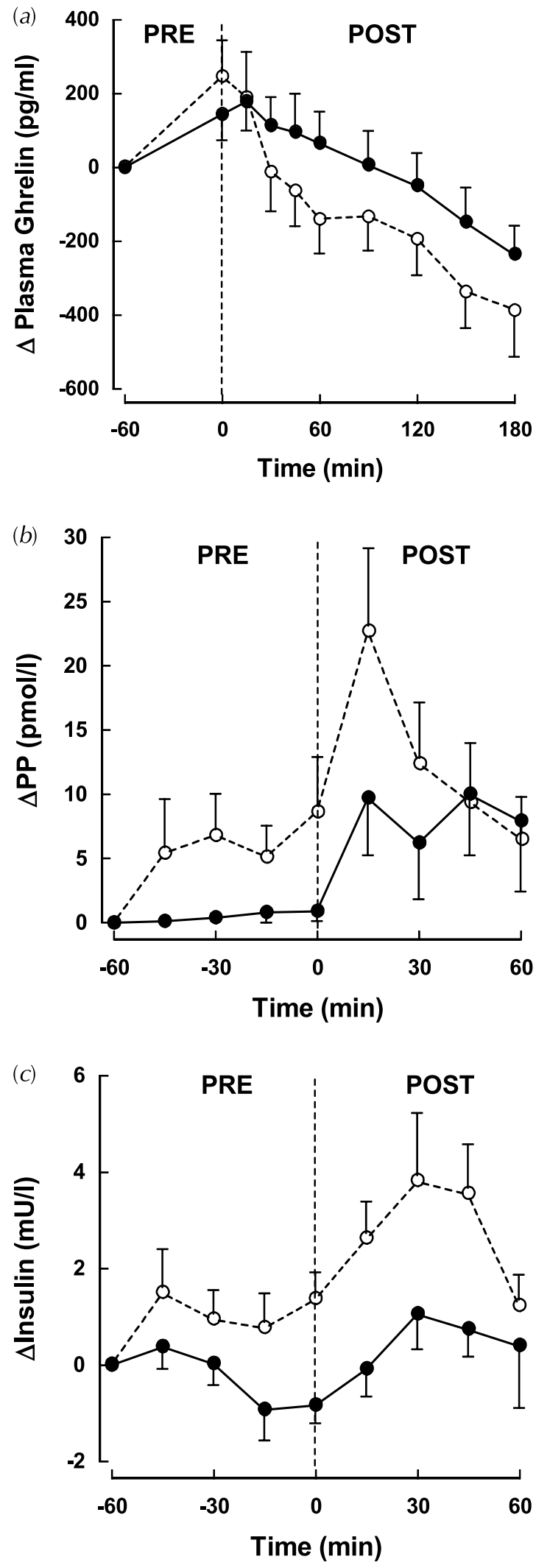

Journal of Endocrinology (2004) 180, 273-281 alone $(24 \cdot 1$ vs $31 \cdot 4 \%)$. The gastric half-emptying time calculated from the ${ }^{13} \mathrm{CO}_{2}$ recovery data (Ghoos et al. 1993) was found to be negatively correlated with the fasting ghrelin concentrations $(r=-0.549, P=0.034)$.

\section{Plasma TG, NEFA and glucose}

In both protocols, there was a significant rise in plasma TG following the oral fat load (time, $P=0 \cdot 001$ ), although there was a significantly higher and more rapid peak attained during the MSF with oral fat study $(P=0 \cdot 001$, Fig. 3a). However, the total TG response as measure by the AUC, was not statistically different between protocols. Peak TG concentration was negatively correlated with the nadir of ghrelin $(P=0.048, r=0.523)$, whereas fasting TG and ghrelin concentrations showed no correlation $(P=0 \cdot 382)$.

Mean plasma NEFA concentrations were not suppressed after the test meal in either study, but were elevated above baseline in the later postprandial period (Fig. 3B). A significantly earlier postprandial NEFA peak was observed when MSF was performed prior to fat ingestion (protocol $\times$ time interaction, $P=0 \cdot 04$ ).

Plasma glucose levels remained unchanged in the preprandial period (Fig. 3C). Following fat ingestion, there was a slight dip in glucose levels evident during both protocols.

\section{Expectorated meals}

The weights of the MSF meal before and after chewing were compared; the mean ( \pm S.E.M.) recovery was $102 \cdot 7 \pm 5 \cdot 2 \%$. The recovery of fat content was $96 \cdot 1 \pm 0.9 \%$ as verified by gas chromatography analysis of expectorant and test meal.

\section{Appetite scores}

When the subjects were asked 'how satisfied do you feel?' and 'how full do you feel?', they answered that they were significantly more satisfied and more full during the MSF than the control meal (protocol $\times$ time $P<0 \cdot 001$, Fig. 4). When asked other questions, such as how much do you

Figure 1 Changes in plasma ghrelin (a), PP (b), and plasma insulin (c) concentrations during an oral fat load preceded by either MSF (O) or no MSF $(\bullet)$. Means \pm S.E.M. $(n=8)$. The prefix PRE represents preprandial, whereas the prefix POST represents postprandial. For ghrelin concentrations, repeated-measures ANOVA showed a significant effect of prior MSF $(P<0 \cdot 001)$. For $P P$, repeated-measures ANOVA showed a significant protocol $\times$ time effect of prior MSF $(P<0 \cdot 01)$. There was a significant preprandial protocol effect $(P=0.002)$ and a significant postprandial (protocol $\times$ time effect, $P=0 \cdot 048$ ). For insulin, repeated-measures ANOVA showed no significant effect of prior MSF, yet there was a significant time effect $(P<0 \cdot 001)$. 


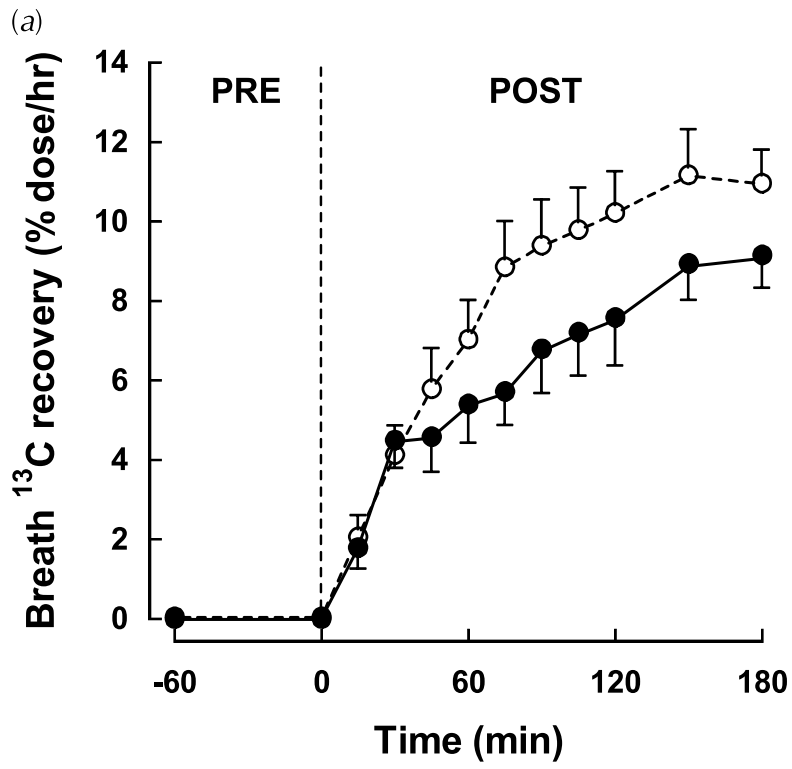

(b)

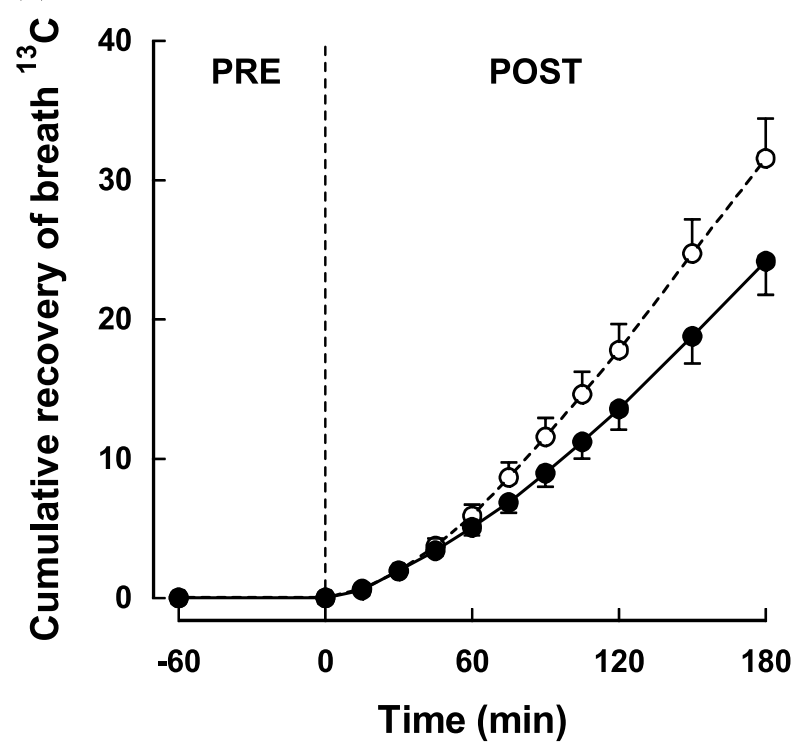

Figure 2 Rate of recovery of ${ }^{13} \mathrm{CO}_{2}$ in breath (a) and cumulative recovery of ${ }^{13} \mathrm{C}(b)$ after the ingestion of $100 \mathrm{mg}\left[1-{ }^{13} \mathrm{C}\right]$ octanoic acid in test meal with $(\bigcirc)$ or without $(\bigcirc)$ prior sham feeding. Means \pm S.E.M. $(n=8)$. The prefix PRE represents preprandial, whereas the prefix POST represents postprandial. Repeated-measures ANOVA showed a significant effect of prior MSF $(P=0 \cdot 001)$ on the mean ${ }^{13} \mathrm{CO}_{2}$ recovery rate.

think you can eat?' and 'how hungry do you feel?', there was no statistical difference between the response given on each protocol. The nadir of ghrelin was positively correlated with the sensation of hunger (nadir vs 'how much do you think you can eat' iAUC $r=0 \cdot 516, P=0 \cdot 049)$.

\section{Discussion}

A typical preprandial and postprandial pattern in circulating concentrations of ghrelin was observed during each protocol, i.e. a preprandial rise in ghrelin prior to food intake followed by a rapid suppression of ghrelin after oral fat consumption. These effects were observed without alterations in either insulin or glucose concentrations outside the normal fasting range. Furthermore, this pattern of ghrelin secretion was exaggerated following MSF. Exaggerated cephalic-phase elevation of ghrelin was observed, as well as rapid suppression of plasma ghrelin concentrations following oral fat.

The effects of vagal stimulation on fasting ghrelin have been indirectly studied in humans. Habitual purging activity in bulimia nervosa patients is associated with increased afferent vagal activity (Faris et al. 2000). Furthermore, patients with bulimia nervosa who are habitual purgers have elevated ghrelin levels compared with those who are not (Tanaka et al. 2002). Rodent studies examining the relationship between vagal activity and fasting ghrelin secretion have provided conflicting data. Electrical stimulation of the vagus nerve in fasting rodents caused an increase in circulating concentrations of ghrelin (Murakami et al. 2002), whereas a separate study showed an elevation in ghrelin concentrations following vagotomy (Lee et al. 2002). However, it must be noted that the measurements of ghrelin were made 14 days after vagotomy, representing long-term changes, rather than the acute changes currently observed. Preprandial elevation of ghrelin is thought to trigger food intake (Cummings et al. 2001). Subjects receiving i.v. ghrelin noted an increase in hunger sensations (Arvat et al. 2001, Wren et al. 2001) and an increase in food consumption when allowed to feed freely (Wren et al. 2001). Ghrelin is known to access the hypothalamic arcuate nucleus through a leaky blood-brain barrier, and increases food intake by activating the neuropeptide Y/Agouti-related peptide pathway (Shintani et al. 2001, Hewson et al. 2002, Lu et al. 2002, Traebert et al. 2002, Bagnasco et al. 2003, Kohno et al. 2003, Riediger et al. 2003, Seoane et al. 2003). Cephalic elevation of ghrelin may upregulate this pathway, leading to not only increased food intake, but also prompt earlier digestive changes such as increased gastrin and gastric acid production (Feldman \& Richardson 1986), and stimulation of both the exocrine and endocrine pancreas (Konturek \& Konturek 2000), thereby aiding faster processing and absorption of food.

We have demonstrated for the first time that plasma ghrelin levels are significantly suppressed following oral TG. Body mass index has been negatively correlated with fasting ghrelin in numerous studies (Ravussin et al. 2001, Tschöp et al. 2001b, Ikezaki et al. 2002, Shiiya et al. 2002), and in the current study $(r=-0.836, P=0 \cdot 01)$. Indeed, fluctuations in weight have been shown to dramatically influence ghrelin concentrations; weight gain decreases 

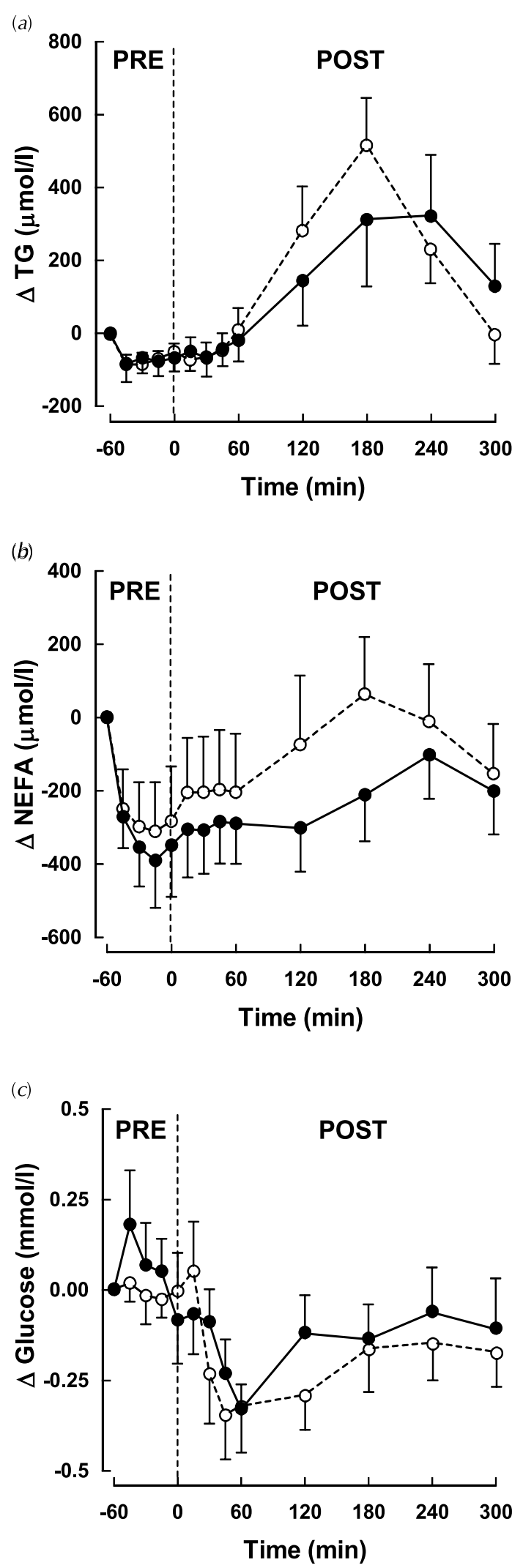

the circulating ghrelin in anorexic patients (Otto et al. 2001), whereas weight loss increases $24 \mathrm{~h}$ ghrelin concentration profiles (Cummings et al. 2002). In rodents, dietary manipulations have shown a decrease in circulating ghrelin following a high-fat diet (Lee et al. 2002). In the current study, the suppression of ghrelin appeared to be related to the magnitude of the peak in postprandial plasma TG $(P=0 \cdot 056)$, which could be interpreted as ghrelin regulation being linked to fat absorption. Furthermore, plasma ghrelin was well correlated with the rate of gastric emptying. Oral fat consumption following vagal stimulation led to more rapid gastric emptying, and more rapid suppression of ghrelin than seen with fat ingestion alone. The suppression of ghrelin was associated with increased feeling of fullness and decreased appetite. This highlights ghrelin's role as a regulator of food intake: a preprandial rise in ghrelin release triggers food intake, whereas low postprandial ghrelin levels suppress food intake.

The mechanisms by which the suppression of postprandial ghrelin is regulated are not entirely clear. Following a normal mixed meal, there is an early postprandial elevation of both glucose and insulin concentrations; therefore, it would be likely that ghrelin is suppressed by either of these two signals. However, the effects of glucose and insulin on ghrelin, when assessed using insulinaemic and glycaemic clamps, have been mixed. Insulin and glucose have had no effect on postprandial ghrelin (Caixas et al. 2002), whereas insulin suppresses ghrelin independently of glucose concentrations (Lucidi et al. 2002, Flanagan et al. 2003, Schaller et al. 2003). In the current study, the glucose concentrations remained static, whereas the postprandial insulin concentrations remained within the fasting range. This has been previously observed following an oral fat tolerance test (Robertson et al. 2002). This suggests that ghrelin can be regulated independently of either insulin or glucose concentrations.

Suppression of ghrelin may be triggered by luminal exposure to free fatty acids in the stomach. Up to $70 \%$ of ghrelin production is derived from the stomach (Date et al. 2000), although the entire amount of circulating ghrelin can be accounted for by the splanchnic bed (Moller et al. 2003). Various gastric secretory and hormonal functions are sensitive to the chemical properties of food within the stomach (McIntosh 1985, Hakanson et al. 1986). However, gastric ghrelin-producing cells situated at the base of the mucosal layer are primarily of the closed type, and as

Figure 3 Changes in plasma TG (a), NEFA (b) and glucose (c) concentrations during an oral fat load preceded by either MSF $(O)$ or no MSF $(\bullet)$. Means \pm S.E.M. $(n=8)$. The prefix PRE represents preprandial, whereas the prefix POST represents postprandial. For TG, repeated-measures ANOVA showed a significant effect of prior MSF $(P<0 \cdot 001)$. For NEFA, repeated-measures ANOVA showed a significant effect of prior MSF $(P=0 \cdot 04)$. For glucose, repeated-measures ANOVA showed no significant effect of prior MSF. 


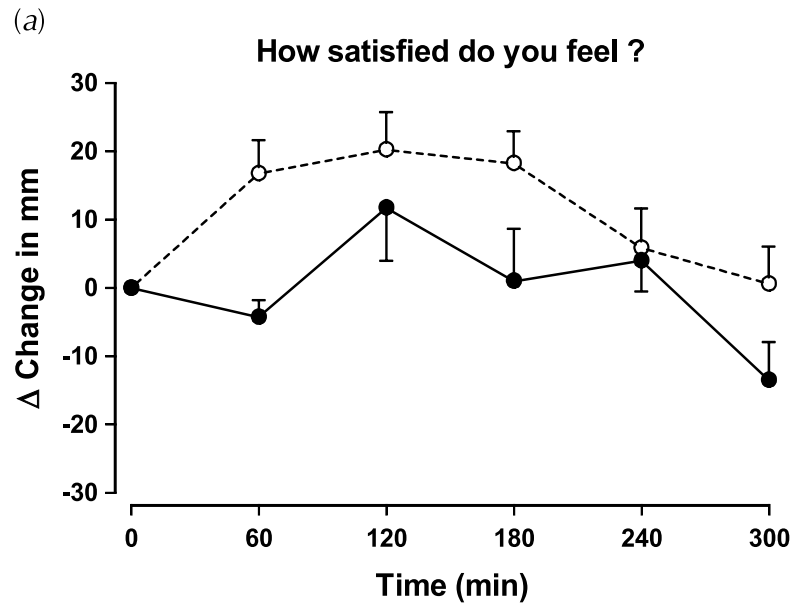

(b)

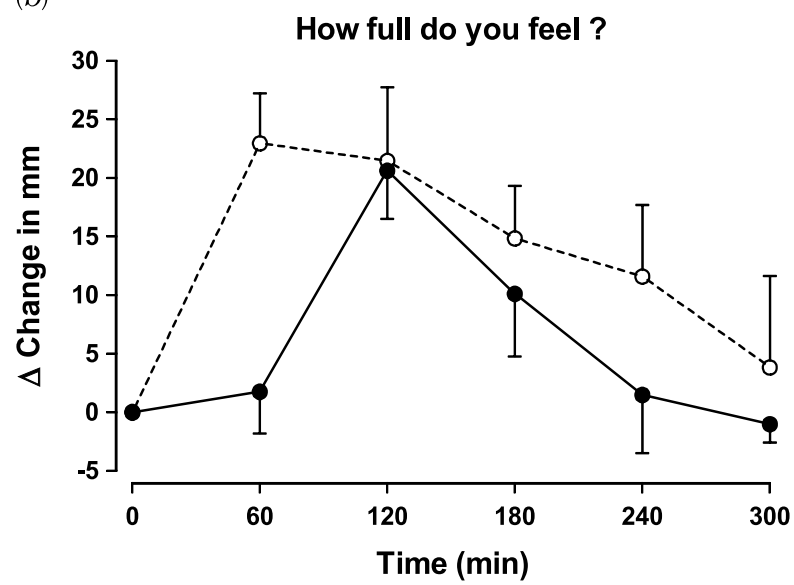

Figure 4 VASs for changes in satisfaction (a) and fullness (b) during an oral fat load preceded by either MSF $(O)$ or no MSF (-). Means \pm S.E.M. $(n=8)$. For both satisfaction and fullness, repeated-measures ANOVA showed a significant effect of prior MSF $(P<0 \cdot 001)$.

such, are not in direct contact with the gastric lumen (Date et al. 2000, Rindi et al. 2002, Sakata et al. 2002). Furthermore, prevention of gastric emptying of glucose in rodents abolishes the suppression of ghrelin normally seen following oral glucose (Williams et al. 2003).

Gastric emptying and the postprandial TG response were closely linked to ghrelin concentrations. This suggests that the entry of dietary fat into the circulation regulates ghrelin secretion. However, in a recent paper, Mohlig et al. (2002), using a heparin-Intralipid infusion, failed to affect circulating ghrelin levels, despite a 3- to 4-fold elevation in plasma NEFA concentrations. It cannot be ruled out that ghrelin suppression may be caused by some component of the intestinally derived lipoproteins interacting with the basolateral side of the X/A cell to suppress the release of ghrelin from the small intestine.
The most plausible explanation is that ghrelin is being regulated by the release of another lipid-induced gastrointestinal hormone. Possible candidate hormones would be small intestinal cholecystokinin (CCK), gastric inhibitory polypeptide and glucagon-like peptide-1 (GLP-1). Ghrelin secretion is influenced by central neural mechanisms originating in the dorsal vagal complex (Lee et al. 2002) in the hypothalamus, an area of the brain in which receptors for both CCK (Schick et al. 1994) and GLP-1 have been localized (Shughrue et al. 1996). However, neither CCK nor GLP-1 is directly affected by cephalic vagal stimulation (Katschinski 2000), yet increased ghrelin suppression occurs following MSF.

In summary, vagal stimulation exaggerates the timecourse of ghrelin responses generally seen in response to food intake, i.e. an increase in preprandial ghrelin and rapid postprandial suppression. The physiological consequences are that dietary fat is more rapidly absorbed and metabolized. Cephalic-phase insulin has been suggested as a key regulator of postprandial glucose tolerance. It may be possible the cephalic elevation of ghrelin performs a similar role for postprandial lipid metabolism.

\section{Acknowledgements}

The authors would like to thank the Biomedical Mass Spectrometry Unit, University of Newcastle-upon-Tyne for analysis of ${ }^{13} \mathrm{CO}_{2}$ samples. R B H held a Medical Research Council Studentship.

\section{Funding}

Supported by grants from the Medical Research Council and the Biotechnology and Biological Sciences Research Council, UK.

\section{References}

Arvat E, Maccario M, Di Vito L, Broglio F, Benso A, Gottero C, Papotti M, Muccioli G, Dieguez C, Casanueva FF et al. 2001 Endocrine activities of ghrelin, a natural growth hormone secretagogue (GHS), in humans: comparison and interactions with hexarelin, a nonnatural peptidyl GHS, and GH-releasing hormone. Journal of Clinical Endocrinology and Metabolism 86 1169-1174.

Bagnasco M, Tulipano G, Melis MR, Argiolas A, Cocchi D \& Muller EE 2003 Endogenous ghrelin is an orexigenic peptide acting in the arcuate nucleus in response to fasting. Regulatory Peptides $\mathbf{1 1 1}$ 161-167.

Caixas A, Bashore C, Nash W, Pi Sunyer F \& Laferrere B 2002 Insulin, unlike food intake, does not suppress ghrelin in human subjects. Journal of Clinical Endocrinology and Metabolism 871902.

Calles Escandon J \& Robbins DC 1987 Loss of early phase of insulin release in humans impairs glucose tolerance and blunts thermic effect of glucose. Diabetes 36 1167-1172.

Cummings DE, Purnell JQ, Frayo RS, Schmidova K, Wisse BE \& Weigle DS 2001 A preprandial rise in plasma ghrelin levels suggests a role in meal initiation in humans. Diabetes 50 1714-1719. 
Cummings DE, Weigle DS, Frayo RS, Breen PA, Ma MK, Dellinger EP \& Purnell JQ 2002 Plasma ghrelin levels after diet-induced weight loss or gastric bypass surgery. New England Journal of Medicine $3461623-1630$

Date Y, Kojima M, Hosoda H, Sawaguchi A, Mondal MS, Suganuma T, Matsukura S, Kangawa K \& Nakazato M 2000 Ghrelin, a novel growth hormone-releasing acylated peptide, is synthesized in a distinct endocrine cell type in the gastrointestinal tracts of rats and humans. Endocrinology 141 4255-4261.

Evans K, Clark ML \& Frayn KN 2001 Carbohydrate and fat have different effects on plasma leptin concentrations and adipose tissue leptin production. Clinical Science 100 493-498.

Faris PL, Kim SW, Meller WH, Goodale RL, Oakman SA, Hofbauer RD, Marshall AM, Daughters RS, Banerjee Stevens D, Eckert ED et al. 2000 Effect of decreasing afferent vagal activity with ondansetron on symptoms of bulimia nervosa: a randomised, double-blind trial. Lancet 355 792-797.

Feldman M \& Richardson CT 1986 Role of thought, sight, smell, and taste of food in the cephalic phase of gastric acid secretion in humans. Gastroenterology 90 428-433.

Fielding BA, Callow J, Owen RM, Samra JS, Matthews DR \& Frayn KN 1996 Postprandial lipemia: the origin of an early peak studied by specific dietary fatty acid intake during sequential meals. American Journal of Clinical Nutrition 63 36-41.

Flanagan DE, Evans ML, Monsod TP, Rife F, Heptulla RA, Tamborlane WV \& Sherwin RS 2003 The influence of insulin on circulating ghrelin. American Journal of Physiology. Endocrinology and Metabolism 284 E313-E316.

Flint A, Raben A, Blundell JE \& Astrup A 2000 Reproducibility, power and validity of visual analogue scales in assessment of appetite sensations in single test meal studies. International Journal of Obesity and Related Metabolic Disorders 24 38-48.

Ghoos YF, Maes BD, Geypens BJ, Mys G, Hiele MI, Rutgeerts PJ \& Vantrappen G 1993 Measurement of gastric emptying rate of solids by means of a carbon-labeled octanoic acid breath test. Gastroenterology 104 1640-1647.

Hakanson R, Bottcher G, Sundler F \& Vallgren S 1986 Activation and hyperplasia of gastrin and enterochromaffin-like cells in the stomach. Digestion 35 23-41.

Haycock GB, Schwartz GJ \& Wisotsky DH 1978 Geometric method for measuring body surface area: a height-weight formula validated in infants, children, and adults. Journal of Pediatrics 93 62-66.

Hewson AK, Tung LY, Connell DW, Tookman L \& Dickson SL 2002 The rat arcuate nucleus integrates peripheral signals provided by leptin, insulin, and a ghrelin mimetic. Diabetes $\mathbf{5 1}$ 3412-3419.

Hopman WP, Jansen JB, Rosenbusch G \& Lamers CB 1987 Cephalic stimulation of gallbladder contraction in humans: role of cholecystokinin and the cholinergic system. Digestion 38 197-203.

Ikezaki A, Hosoda H, Ito K, Iwama S, Miura N, Matsuoka H, Kondo C, Kojima M, Kangawa K \& Sugihara S 2002 Fasting plasma ghrelin levels are negatively correlated with insulin resistance and PAI-1, but not with leptin, in obese children and adolescents. Diabetes 51 3408-3411.

Jackson KG, Robertson MD, Fielding BA, Frayn KN \& Williams CM 2001 Second meal effect: modified sham feeding does not provoke the release of stored triacylglycerol from a previous high-fat meal. British Journal of Nutrition 85 149-156.

Katschinski M 2000 Nutritional implications of cephalic phase gastrointestinal responses. Appetite 34 189-196.

Kohno D, Gao HZ, Muroya S, Kikuyama S \& Yada T 2003 Ghrelin directly interacts with neuropeptide-Y-containing neurons in the rat arcuate nucleus: $\mathrm{Ca}^{2+}$ signaling via protein kinase $\mathrm{A}$ and $\mathrm{N}$-type channel-dependent mechanisms and cross-talk with leptin and orexin. Diabetes 52 948-956.

Kojima M, Hosoda H, Date Y, Nakazato M, Matsuo H \& Kangawa K 1999 Ghrelin is a growth-hormone-releasing acylated peptide from stomach. Nature 402 656-660.
Konturek SJ \& Konturek JW 2000 Cephalic phase of pancreatic secretion. Appetite 34 197-205.

Lee HM, Wang G, Englander EW, Kojima M \& Greeley GH Jr 2002 Ghrelin, a new gastrointestinal endocrine peptide that stimulates insulin secretion: enteric distribution, ontogeny, influence of endocrine, and dietary manipulations. Endocrinology 143 185-190.

Lu S, Guan JL, Wang QP, Uehara K, Yamada S, Goto N, Date Y, Nakazato M, Kojima M, Kangawa K et al. 2002 Immunocytochemical observation of ghrelin-containing neurons in the rat arcuate nucleus. Neuroscience Letters 321 157-160.

Lucidi P, Murdolo G, Di Loreto C, De Cicco A, Parlanti N, Fanelli C, Santeusanio F, Bolli GB \& De Feo P 2002 Ghrelin is not necessary for adequate hormonal counterregulation of insulin-induced hypoglycemia. Diabetes 51 2911-2914.

Maes BD, Geypens BJ, Ghoos YF, Hiele MI \& Rutgeerts PJ 1998 ${ }^{13} \mathrm{C}$-octanoic acid breath test for gastric emptying rate of solids. Gastroenterology 114 856-859.

Masuda Y, Tanaka T, Inomata N, Ohnuma N, Tanaka S, Itoh Z, Hosoda H, Kojima M \& Kangawa K 2000 Ghrelin stimulates gastric acid secretion and motility in rats. Biochemical and Biophysical Research Communications 276 905-908.

McCowen KC, Maykel JA, Bistrian BR \& Ling PR 2002 Circulating ghrelin concentrations are lowered by intravenous glucose or hyperinsulinemic euglycemic conditions in rodents. Journal of Endocrinology 175 R7-R11.

McIntosh CH 1985 Gastrointestinal somatostatin: distribution, secretion and physiological significance. Life Sciences 37 2043-2058.

Mohlig M, Spranger J, Otto B, Ristow M, Tschöp M \& Pfeiffer AF 2002 Euglycemic hyperinsulinemia, but not lipid infusion, decreases circulating ghrelin levels in humans. Journal of Endocrinological Investigation 25 RC36-RC38.

Moller N, Nygren J, Hansen TK, Orskov H, Frystyk J \& Nair KS 2003 Splanchnic release of ghrelin in humans. Journal of Clinical Endocrinology and Metabolism 88 850-852.

Murakami N, Hayashida T, Kuroiwa T, Nakahara K, Ida T, Mondal MS, Nakazato M, Kojima M \& Kangawa K 2002 Role for central ghrelin in food intake and secretion profile of stomach ghrelin in rats. Journal of Endocrinology 174 283-288.

Naim M, Kare MR \& Merrie AM 1978 Effects of oral stimulation on the cephalic phase of pancreatic exocrine in dogs. Physiology and Behavior 20 563-570.

Nakazato M, Murakami N, Date Y, Kojima M, Matsuo H, Kangawa K \& Matsukura S 2001 A role for ghrelin in the central regulation of feeding. Nature 409 194-198.

Otto B, Cuntz U, Fruehauf E, Wawarta R, Folwaczny C, Riepl RL, Heiman ML, Lehnert P, Fichter M \& Tschöp M 2001 Weight gain decreases elevated plasma ghrelin concentrations of patients with anorexia nervosa. European Journal of Endocrinology 145 669-673.

Ravussin E, Tschöp M, Morales S, Bouchard C \& Heiman ML 2001 Plasma ghrelin concentration and energy balance: overfeeding and negative energy balance studies in twins. Journal of Clinical Endocrinology and Metabolism 86 4547-4551.

Riediger T, Traebert M, Schmid HA, Scheel C, Lutz TA \& Scharrer E 2003 Site-specific effects of ghrelin on the neuronal activity in the hypothalamic arcuate nucleus. Neuroscience Letters 341 151-155.

Rindi G, Necchi V, Savio A, Torsello A, Zoli M, Locatelli V, Raimondo F, Cocchi D \& Solcia E 2002 Characterisation of gastric ghrelin cells in man and other mammals: studies in adult and fetal tissues. Histochemistry and Cell Biology 117 511-519.

Robertson MD, Jackson KG, Williams CM, Fielding BA \& Frayn KN 2001 Prolonged effects of modified sham feeding on energy substrate mobilization. American Journal of Clinical Nutrition $\mathbf{7 3}$ 111-117.

Robertson MD, Mason AO \& Frayn KN 2002 Timing of vagal stimulation affects postprandial lipid metabolism in humans. American Journal of Clinical Nutrition 76 71-77. 
Saad MF, Bernaba B, Hwu CM, Jinagouda S, Fahmi S, Kogosov E \& Boyadjian R 2002 Insulin regulates plasma ghrelin concentration. Journal of Clinical Endocrinology and Metabolism 87 3997-4000.

Sakata I, Nakamura K, Yamazaki M, Matsubara M, Hayashi Y, Kangawa K \& Sakai T 2002 Ghrelin-producing cells exist as two types of cells, closed- and opened-type cells, in the rat gastrointestinal tract. Peptides 23 531-536.

Schaller G, Schmidt A, Pleiner J, Woloszczuk W, Wolzt M \& Luger A 2003 Plasma ghrelin concentrations are not regulated by glucose or insulin: a double-blind, placebo-controlled crossover clamp study. Diabetes 52 16-20.

Schick RR, Schusdziarra V, Yaksh TL \& Go VL 1994 Brain regions where cholecystokinin exerts its effect on satiety. Annals of the New York Academy of Sciences 713 242-254.

Seoane LM, Lopez M, Tovar S, Casanueva FF, Senaris R \& Dieguez C 2003 Agouti-related peptide, neuropeptide Y, and somatostatin-producing neurons are targets for ghrelin actions in the rat hypothalamus. Endocrinology 144 544-551.

Shiiya T, Nakazato M, Mizuta M, Date Y, Mondal MS, Tanaka M, Nozoe S, Hosoda H, Kangawa K \& Matsukura S 2002 Plasma ghrelin levels in lean and obese humans and the effect of glucose on ghrelin secretion. Journal of Clinical Endocrinology and Metabolism 87 240-244.

Shintani M, Ogawa Y, Ebihara K, Aizawa Abe M, Miyanaga F, Takaya K, Hayashi T, Inoue G, Hosoda K, Kojima M et al. 2001 Ghrelin, an endogenous growth hormone secretagogue, is a novel orexigenic peptide that antagonizes leptin action through the activation of hypothalamic neuropeptide Y/Y1 receptor pathway. Diabetes 50 227-232.

Shughrue PJ, Lane MV \& Merchenthaler I 1996 Glucagon-like peptide-1 receptor (GLP1-R) mrna in the rat hypothalamus. Endocrinology 137 5159-5162.

Symonds EL, Butler RN \& Omari TI 2000 Assessment of gastric emptying in the mouse using the $\left[{ }^{13} \mathrm{C}\right]$-octanoic acid breath test. Clinical and Experimental Pharmacology and Physiology 27 671-675.

Tanaka M, Naruo T, Muranaga T, Yasuhara D, Shiiya T, Nakazato M, Matsukura S \& Nozoe S 2002 Increased fasting plasma ghrelin levels in patients with bulimia nervosa. European Journal of Endocrinology 146 R1-R3.

Teff KL \& Engelman K 1996 Oral sensory stimulation improves glucose tolerance in humans: effects on insulin, C-peptide, and glucagon. American Journal of Physiology 270 R1371-R1379.

Toshinai K, Mondal MS, Nakazato M, Date Y, Murakami N, Kojima M, Kangawa K \& Matsukura S 2001 Upregulation of ghrelin expression in the stomach upon fasting, insulin-induced hypoglycemia, and leptin administration. Biochemical and Biophysical Research Communications 281 1220-1225.

Traebert M, Riediger T, Whitebread S, Scharrer E \& Schmid HA 2002 Ghrelin acts on leptin-responsive neurones in the rat arcuate nucleus. Journal of Neuroendocrinology 14 580-586.

Tschöp M, Smiley DL \& Heiman ML 2000 Ghrelin induces adiposity in rodents. Nature 407 908-913.

Tschöp M, Wawarta R, Riepl RL, Friedrich S, Bidlingmaier M, Landgraf R \& Folwaczny C 2001a Post-prandial decrease of circulating human ghrelin levels. Journal of Endocrinological Investigation 24 RC19-RC21.

Tschöp M, Weyer C, Tataranni PA, Devanarayan V, Ravussin E \& Heiman ML $2001 b$ Circulating ghrelin levels are decreased in human obesity. Diabetes $\mathbf{5 0} 707-709$.

Williams DL, Cummings DE, Grill HJ \& Kaplan JM 2003 Meal-related ghrelin suppression requires postgastric feedback. Endocrinology 144 2765-2767.

Wren AM, Seal LJ, Cohen MA, Brynes AE, Frost GS, Murphy KG, Dhillo WS, Ghatei MA \& Bloom SR 2001 Ghrelin enhances appetite and increases food intake in humans. Journal of Clinical Endocrinology and Metabolism 865992.

Received in final form 21 October 2003

Accepted 23 October 2003

Made available online as an

Accepted Preprint 3 November 2003 